\title{
RUPTURA GERACIONAL INDUZIDA E ESTRATÉGIAS DE GESTÃO: A EXPERIÊNCIA NAS MONTADORAS DO SUL FLUMINENSE
}

\author{
Marco Aurélio Santana
}

\begin{abstract}
RESUMO: Entre o arsenal de práticas implementadas pelas empresas com as mudanças operadas no mundo do trabalho, nas décadas recentes, a indução do corte entre gerações na força de trabalho pode ser considerada uma das mais frequentes e eficazes. $\mathrm{O}$ que está em jogo aqui é uma ruptura geracional induzida, que guarda relaçôes com as mudanças objetivas ocorridas no setor industrial, mas que, sobretudo, são acentuadas e utilizadas no sentido de minar o potencial identitário e coletivo dos trabalhadores. Um dos modelos mais bem acabados dessa prática foi o caso francês, analisado com maestria no clássico Retour sur la condition ouvrière, de Stephane Beaud e Michel Pialoux. A ideia no presente artigo é analisar o caso particular de uso dessa estratégia pelas montadoras instaladas no sul fluminense, avaliando seus impacto concretos no que diz respeito 1) ao possível desarmar da classe operária e de sua forma de resistência; 2) à ruptura geracional; 3) à separação entre "empregáveis" e "não empregáveis"; 4) à possível desarticulação do coletivo operário e 5) à erosão das base tradicionais de transmissão de valores identitários.
\end{abstract}

Palavras-chave: Trabalhadores. Trabalho. Gerações. Estratégias gerenciais.

Doutor em Sociologia e professor do Programa de Pós-Graduação em Sociologia e Antropologia da Universidade Federal do Rio de Janeiro (UfRJ).E-mail: msantana@ifcs.ufrj.br

Gostaria de agradecer a Kimi Tomizaki pela leitura atenta e pelas sugestôes detalhadas e fundamentais que fez ao texto.

Educ. Soc., Campinas, v. 31, n. 111, p. 371-389, abr.-jun. 2010

Disponível em <http://www.cedes.unicamp.br> 
Ruptura geracional induzida e estratégias de gestão...

THE INDUCED GENERATIONAL RUPTURE AND THE STRATEGIES OF MANAGEMENT: THE EXPERIENCE OF CAR MANUFACTURERS IN SOUTHERN RIO DE JANEIRO

ABSTRACT: The induced generation gap has been one of the most prominent and successful tool within the strategies implemented by the companies in the recent years. At stake here is an induced generation gap, in keeping with the objective changes that have taken place in the industrial sector, which both reinforces them and undermines the identity and collective potential of workers. One of the best examples of this mechanism is the French case analyzed by Stephane Beaud e Michel Pialoux in Retour sur la condition ouvrière. This paper analyzes the particular case of the automotive industry in Southern Rio de Janeiro. It evaluates its concrete impacts taking into account: 1) the possible weakening of the working class and of its forms of resistance; 2) the generation gap; 3) the separation between "employable" and "unemployable"; 4) the possible disarticulation of worker collective actions and 5) the erosion of the transmission of traditional identity values.

Key words: Workers. Work. Generation. Management.

\section{Introdução}

$\mathrm{O}$ local de trabalho e as relações que se estabelecem em seus domínios são fundamentais na formação da identidade dos trabalhadores e do grupo de trabalhadores. Isso ocorre a partir de processos de aprendizagens, formais e informais, ininterruptas e de variados tipos. Entre eles, temos um repertório que vai desde os de caráter objetivo e técnico, ligados diretamente ao processo produtivo, até os simbólicos, que estão relacionados ao universo dos valores, comportamentos e princípios que organizam, estruturam e orientam os grupos. Seria exatamente pela via desses mecanismos de socialização que as novas geraçóes de trabalhadores aprenderiam com os mais velhos e experientes os significados da condição operária. Assim, aprenderiam a ser no mundo de uma determinada forma, bem como a se ver neste próprio mundo.

Nesses termos, pode-se dizer que o chamado "mundo do trabalho" é total e constantemente perpassado por processos e práticas de cunho educativo. Isso pode se dar, por exemplo, a partir de práticas 
que ocorrem no interior dos locais de trabalho, ou mesmo pelo valor atribuído pelas empresas às certificações escolares. O que vem ocorrendo nas últimas décadas é um movimento particular que tem modificado o andamento tradicional dessa trajetória. A entrada de novas gerações nos locais de trabalho, com um perfil bastante característico, marcado pela alta escolaridade e qualificação, tem produzido uma situação na qual o trabalhador não é socializado enquanto tal nos locais de trabalho. Com isso, ele perderia a possibilidade de obter e incorporar, junto ao que seriam os conhecimentos técnicos, também determinados valores e comportamentos de ordem política. Tudo isso tem tido um grande impacto sobre a formação de novos grupos operários e, em decorrência, sobre a forma de ser tanto de suas identidades, como de sua vida organizativa e mobilizatória.

Assim, o que se percebe é que, entre o arsenal de práticas implementadas com as mudanças operadas no mundo do trabalho, nas décadas recentes, a precipitação do corte entre gerações de trabalhadores figura entre as mais frequentes e eficazes. O que está em jogo aqui é uma ruptura geracional induzida, que guarda relaçóes com as mudanças objetivas ocorridas no setor industrial, mas que, sobretudo, é acentuada e utilizada estrategicamente no sentido de minar o potencial identitário e coletivo dos trabalhadores. Mais do que um processo que se dava em termos de substituição progressiva de grupos de trabalhadores em termos etários, em que, sequencialmente, os mais jovens entravam no mundo do trabalho e iam sendo socializados em valores construídos e presentes nos grupos operários, o que as empresas buscaram foi, em um contexto de transformações, precipitar e induzir essa ruptura geracional.

De forma geral, os espaços de trabalho passaram a ser marcados pelo recrutamento seletivo, em que a prioridade recaía sobre os jovens trabalhadores em detrimento daqueles com mais idade. Claramente, isso rompia, de forma abrupta, com toda uma construção de ser e de mundo, de identidades, de vínculos, de sociabilidade, a qual, outrora, marcou a vida de trabalho e organização dos trabalhadores, principalmente no que diz respeito aos seus aspectos coletivos. Ainda que de forte cunho político, este processo se deu sempre sob uma justificativa técnica, na qual a questão da escolaridade, do dinamismo, das aptidóes à mudança, entre outras, surgia como pilares de sustentação. 
Ruptura geracional induzida e estratégias de gestão...

Um dos modelos mais bem acabados dessa prática foi o caso francês, analisado com maestria no clássico Retour sur la condition ouvrière, de Stephane Beaud e Michel Pialoux (2004). Em um período de extremas mudanças no chão de fábrica, que foram os anos de 1980, marco de introdução do chamado modelo japonês, na França, os autores conseguem captar o duro impacto de tais mudanças sobre a vida cotidiana dos trabalhadores e como isso vai minando as suas possibilidades de resistência. O coletivo operário vai sendo desestruturado. A estratégia usada pela empresa foi a da incorporação de novas técnicas gerenciais de inspiração toyotista e o aumento do desemprego, o que acabou impondo um processo de reconfiguração das identidades no mundo do trabalho. Além disso, essa situação veio associada ao recrutamento em grande escala de jovens geraçôes de trabalhadores, provocando uma pane nos mecanismos tradicionais de transmissão intergeracional de valores identitários do "grupo operário".

Para Beaud e Pialoux, tratava-se de um movimento para desarmar a "classe operária" de sua capacidade de dar sentido às experiências vividas no mundo do trabalho para transformá-la em uma "classe fantasma", na medida em que, em duas décadas, passou de centro das atençôes político-sociais para o quase esquecimento. No entanto, para os autores, apesar desse obscurecimento no espaço público, a questão operária continuaria, mais do que nunca, atual. Seria necessário pensar agora o mundo operário sem a "classe operária". Estaríamos diante do que poderia ser chamado de uma "nova condição operária", para a qual deveríamos "retornar".

$\mathrm{Na}$ experiência francesa, as novas configuraçóes industriais implicaram a "homogeneização social e profissional" dos trabalhadores e, com isso,

(...) a aceleração da ruptura geracional e uma triagem seletiva que permitem, por um lado, afastar os operários "não empregáveis" ou "que atrapalham" (aqueles que, por exemplo, ousam ainda falar de sindicato) e, por outro, manter apenas aqueles que, segundo a empresa, são mais suscetíveis de se curvar às novas exigências. (Beaud \& Pialoux, 2004, p. 113)

Com a ruptura geracional, estabeleceram-se critérios de recrutamento de "jovens operários", que incluem em seu portfólio, entre outros, competência, adaptabilidade, capacidade, motivação e potencial. 
A proposta deste artigo seria analisar, à luz do já clássico estudo citado anteriormente, os efeitos dos processos de ruptura geracional induzidos pelo capital sobre os trabalhadores da indústria automobilística instalada na região sul do estado do Rio de Janeiro, avaliando seus impactos concretos no que diz respeito 1) ao possível desarmar da classe operária e de suas formas de resistência; 2) à ruptura geracional; 3) à separação entre "empregáveis" e "não empregáveis"; 4) à desarticulação do coletivo operário e 5) à erosão das bases tradicionais de transmissão de valores identitários.

\section{O sul fluminense no mapa do setor automotivo}

A sociedade brasileira passou por rápidas e profundas transformações nos anos de 1990, com consequências e desdobramentos que nos alcançam até hoje. O seu mundo do trabalho foi reestruturado de alto a baixo. O setor automotivo, global e local, foi atingido substancialmente por esse processo. Em nosso país, a partir de uma política de abertura de mercado no início daquela década, as montadoras multinacionais não só investiram mais na construção de novas fábricas, como também buscaram novas áreas (greenfields - baixa ou nenhuma tradição industrial e baixa ou nenhuma densidade sindical) fora do que seriam as zonas tradicionais (brownfields - forte tradição industrial e alta densidade sindical) de produção de veículos. Aberto este espaço, a região sul do estado do Rio de Janeiro, como outras, pleiteia os novos investimentos automotivos. Isso se dá na perspectiva de que a localidade pudesse se tornar um polo de desenvolvimento no setor, assemelhando-se a outras experiências existentes.

Por razões óbvias, a questão da espacialidade dos novos investimentos no setor teve forte presença no debate sobre as transformações na cadeia automotiva no Brasil. Embora certa desconcentração industrial já atingisse os principais estados da região Sudeste do país, desde décadas anteriores, a abertura comercial dos anos recentes revelou um processo diferenciado, sobretudo no que se refere ao setor automobilístico. A "fuga" das regiōes ditas tradicionais, como o ABC paulista, ${ }^{1}$ e a dura disputa entre estados e municípios por novos investimentos, precipitada pela implantação de um "novo regime automotivo", abriram uma verdadeira "guerra" de vantagens e renúncias fiscais com a intenção 
Ruptura geracional induzida e estratégias de gestão...

de produzir atrativos para empresas desse corte (Arbix, 2000; Ramalho \& Santana, 2001, 2002).

$\mathrm{O}$ estado do Rio de Janeiro foi um jogador bastante ativo nesse processo de atração de novas inversões, lançando mão dos mais variados meios e argumentos, e, com os esforços conjugados dos governos no nível estadual e municipal e a influência de seus representantes políticos, teve êxito na atração de duas empresas montadoras de peso para o estado, mais precisamente para a região sul fluminense: a Volkswagen Caminhóes, instalada na cidade de Resende (1996), e a PSA PeugeotCitroën (2001), instalada na contígua cidade de Porto Real. Por essa razão, a região nutriu elevadas pretensões quanto aos desdobramentos sociais e econômicos desse processo de renovação industrial e quanto à criação de políticas, com o objetivo de preparar a localidade para a constituição de um polo metal-mecânico, com base na indústria automobilística. Uma indústria com esse corte e desse porte abria a possibilidade de ampliação do mercado de trabalho, direta e indiretamente. $\mathrm{O}$ interesse, no sentido de que a região pudesse receber ainda mais investimentos, nesta e em outras áreas, se fez presente, de forma constante - ainda que, ao longo do tempo, tenha se mostrado aquém do "fantasiado" nas narrativas -, na fala de praticamente todos os atores locais. De todo modo, a região passaria a constar no mapa do setor automotivo global e local.

No que diz respeito ao perfil dos trabalhadores demandados por esse novo mercado que se abria, a questão da escolaridade e da qualificação assumia um lugar de destaque. Deve-se dizer que esse processo se deu fortemente associado a um discurso, de claros efeitos práticos, pautado pela exigência de escolarização e qualificação dos trabalhadores a serem recrutados.

Como se viu, em geral, pelo país, repassava-se para os trabalhadores a responsabilidade sobre sua entrada e manutenção no mercado de trabalho. A tônica, ao longo de toda a década de 1990, foi a pressão sobre os trabalhadores para que se tornassem "empregáveis", aumentando sua "empregabilidade", a partir dos cursos de qualificação. Foi sensível, nesse contexto, um processo de ampliação do sistema de ensino nacional, em particular o ensino superior. Isso ofereceu às novas gerações a possibilidade de uma maior escolarização em relação àquela conseguida por seus pais. Tomizaki (2006) assinala que 
isso tem formado um exército de reserva de força de trabalho escolarizado e qualificado, diferentemente da geração anterior, o que tem aumentado a tensão intergeracional mesmo nos espaços em que a tradição operária já se encontrava sedimentada, como no ABC paulista. Segundo a autora, o que se dá é que o alongamento da escolarização, com o acesso a níveis cada vez mais altos de ensino, pode conduzir a uma série de contradições internas ao grupo operário e às famílias operárias.

As empresas, a região e as estratégias

A escolha da região sul fluminense - Resende e Porto Real, em particular - para esse novo tipo de investimento deveu-se a diversos fatores, em uma combinação de estratégias distintas tanto da parte das empresas, quanto dos governos federal, estadual e municipal. Primeiro, o estado do Rio de Janeiro se encaixava na estratégia das empresas de estarem geograficamente próximas do principal mercado consumidor brasileiro e acessível ao mercado sul-americano (Ramalho \& Santana, 2001, 2002).

Por outro lado, a nova localização evitava a concentração industrial do $\mathrm{ABC}$ paulista e, sonho constante das empresas, deixava para trás a conhecida força política que aquele sindicalismo fora assumindo após longas jornadas de organização e mobilização nos anos de 1970-1980. Por último, o suporte político do governo federal permitiu ao governo do estado do Rio de Janeiro apresentar condições para atrair as montadoras e suas fornecedoras, com a oferta de um sem número de incentivos.

Os trâmites da negociação que efetivou a vinda da VW e da PSA tiveram a mediação de aspectos técnicos e políticos imbricados. A escolha da localidade para a nova fábrica da vw, por exemplo, foi um processo com várias fases, sendo necessárias infindáveis informações para satisfazer as solicitações da empresa, que visou condições ótimas para a instalação de sua primeira fábrica de caminhões no mundo.

O governo estadual, em busca do que seria protagonismo, entrou com sua parcela de recursos, colocando à disposição da VW condições de infraestrutura muitíssimo favoráveis. Foram gastos milhões de dólares na construção de equipamentos, tais como estação de força elétrica, linha nova de canalização de gás e estrada asfaltada, e em recursos 
Ruptura geracional induzida e estratégias de gestão...

para que o poder público local providenciasse postes de luz, placas de sinalização, água, esgoto, transporte e telecomunicações. A montadora teria ótimas condiçõoes de instalação e operação.

O município de Resende, embora tenha tido um papel que pode ser considerado secundário nas decisōes principais sobre a vinda da VW, teve a seu favor não só a localização estratégica, mas também uma especial atenção à criação de uma infraestrutura para o crescimento industrial (Ramalho \& Santana, 2001, 2002). A vinda da vw transformou-se em argumento para um processo de disputa política municipal que resultou, concretamente, na emancipação do município de Porto Real, em 1995. Nesse quadro, a localização da fábrica tornou-se moeda de troca, permanecendo em Resende sob a condição de que a emancipação de Porto Real se tornasse realidade. Em seguida, Porto Real foi escolhida para ser a base de instalação da PSA Peugeot-Citroën e de seus fornecedores.

No que diz respeito às negociações de implantação, o caso da PSA foi distinto daquele da Volkswagen. Mesmo que os mecanismos de atração utilizados tenham sido, de certa forma, basicamente os mesmos - em uma cesta da qual constaram doaçóes de terras, incentivos fiscais, salários baixos e uma infraestrutura regional que atendia bastante bem aos interesses de expansão da firma -, a PSA construía sua primeira fábrica no Brasil visando o MERCOSUL, mercado que assumiu prioridade nas estratégias globais da empresa. Foram necessárias muitas idas e vindas entre Rio de Janeiro e Paris.

Neste caso, a disputa foi mais acirrada até os últimos momentos. Isso porque outros estados investiam fortemente para atrair a montadora. Numa outra ponta da estratégia e incentivos, reforçando a posição do pleito, apresentou-se uma novidade baseada pela participação do próprio estado do Rio de Janeiro como acionista da empresa, com parcela considerável no seu capital, ao que se acresceu um generoso empréstimo do BNDES.

Tendo sido a primeira empresa do setor a se instalar na localidade, acabou por recair sobre a vw uma gama mais elevada de expectativas. Com o anúncio oficial de Resende como local da nova fábrica, criou-se um clima bastante otimista sobre os benefícios para o município e para o mercado de trabalho local. A questão dos empregos foi bastante explorada na época tanto por políticos em campanha, quanto 
pelo comércio. Contudo, ainda hoje se percebe a grande distância entre os postos de trabalho anunciados e os concretizados. Isso ocorre porque, devido a sua forma de organização produtiva, de tipo consórcio modular, a vW não trouxe o esperado em termos de empregos diretos (Abreu, Beynon \& Ramalho, 2000; Ramalho \& Santana, 2001, 2002).

Ao contrário da Vw, a PSA Peugeot-Citroën adotou a estratégia de trazer para perto de si a sua rede principal de fornecedores, alocados no tecnopolo, situado no entorno da fábrica. Beneficiada pela doação de terrenos contíguos ao da montadora, essa oportunidade propiciou a formação de um cinturão de empresas para atender as demandas da produção.

De qualquer modo, tendo em vista as próprias características desse tipo de indústria, pode-se constatar que houve um crescimento das atividades econômicas, especialmente de alguns setores, e os municípios voltaram-se para atender as demandas trazidas pelos novos empreendimentos.

Além das estratégias de implantação, as montadoras empreenderiam movimentos no sentido do recrutamento de força de trabalho e de gestão das relações de trabalho. No que diz respeito à contratação de trabalhadores, apesar de em número inferior às inflacionadas expectativas, a Vw resolveu recrutar a maioria dos seus trabalhadores da própria região e, mais adiante, a PSA seguiria o mesmo percurso. Devemos lembrar que a instalação das duas empresas na região estabeleceu a criação de uma primeira geração de trabalhadores metalúrgicos no setor automotivo. Foi necessária a formação de uma classe operária específica do setor, até então inexistente na localidade.

Nesse processo, a participação do Serviço Nacional de Aprendizagem Industrial (SENAI) foi fundamental, ao servir de intermediário na formação e convocação de seus alunos para ocupar os novos postos de trabalho gerados pelas montadoras. As empresas buscaram uma associação imediata com esse órgão de formação de trabalhadores, não só efetivando seu aparelhamento e atualização com instrumental para cursos ligados às demandas do setor automotivo, como oferecendo, no caso da Vw, cursos e convênios dentro da fábrica. Tal associação teve claro impacto na atuação do SENAI na região. No caso da montadora francesa, ela não só enviou formadores para cursos na França, como uma minilinha de montagem foi construída dentro daquele centro de formação, 
Ruptura geracional induzida e estratégias de gestão...

para que os alunos se adequassem às exigências e demandas da montadora.

O SENAI tem já longa importância e tradição no que diz respeito aos processos de ensino e formação da classe operária brasileira. Quando de sua implantação por Getúlio Vargas, em janeiro de 1942, o órgão buscava dar formação à força de trabalho para a incipiente indústria de base do país. Contudo, deve-se dizer também que, desde a sua criação, esta instituição foi pensada como um instrumento de limitação e bloqueio para impedir que os velhos e experientes trabalhadores transmitissem às novas geraçôes, junto com o conhecimento do trabalho, o que seriam também comportamentos e atitudes políticas. $\mathrm{O}$ SENAI traria a si a responsabilidade de transmissão do conhecimento técnico do trabalho, filtrado de qualquer traço político. No caso por nós analisado, esta instituição parece ter encontrado as condições ideais para por em marcha tal concepção.

A perspectiva das empresas de contratar trabalhadores com o segundo grau completo, dadas as características da educação no Brasil e o perfil educacional histórico de sua classe trabalhadora, forçou para baixo a idade dos operários. Assim, o que temos nas montadoras é uma força de trabalho jovem e com grau de escolaridade relativamente elevado, de baixa tradição industrial e sem experiência sindical. Além disso, as empresas têm priorizado a contratação de trabalhadores locais, o que tem promovido uma verdadeira acorrida aos cursos de qualificação e movido o mercado de trabalho local.

O survey realizado por Ramalho e Santana na vw, em 2001, além de demonstrar claramente uma força de trabalho jovem, majoritariamente local e de alta escolaridade (Ramalho \& Santana, 2002, 2006b), aponta que $42 \%$ dos pais dos trabalhadores entrevistados tiveram um grau de escolarização reduzido em comparação a seus filhos.

Um ponto que pode matizar o quadro geral da formação dessa classe operária mais jovem e escolarizada, por fora de quadros de socialização e transmissão intergeracionais, está na indicação de que, no que diz respeito ao trabalho anterior dos pais, um número importante quanto à tradição familiar na profissão: 13\% dos pais dos trabalhadores da fábrica são ou foram metalúrgicos e 15\% carregam uma tradição de emprego na indústria. No entanto, a maioria trabalhou ou trabalha no setor de serviços $(37 \%)$ ou em atividades por conta própria 
(19\%) (Ramalho \& Santana, 2002, 2006b). Assim, apesar de não ter sido possível avaliar a fundo tal tradição, pode-se supor os possíveis veios de transmissão familiar quanto à profissão, mas também intuir os possíveis conflitos oriundos de uma nova inserção no mundo e apropriação de seus valores, bem como das expectativas quanto ao trabalho e seus horizontes.

Essa estratégia gerencial de recrutamento de jovens se deu articulada com outra de prevenir e evitar a contratação de operários "mais experientes". Houve mesmo uma tentativa, bem sucedida, de evitar que antigos operários da Companhia Siderúrgica Nacional (CSN), situada na mesma região, na cidade de Volta Redonda, e palco de elevada tradição operária e sindical, com decorrente densidade de conflitos trabalhistas, pudessem ser recrutados para o trabalho na montadora. Como outrora, em um sonho de duvidosa realização, visava-se um "cordão sanitário", impedindo que o "veneno" sindical e conflitivo pudesse "contaminar" a tenra classe operária que se levantava do chão em tão pouco tempo.

As empresas têm usufruído, como é constante nesse tipo de experiência, da estratégia do greenfield para garantir vantagens em termos salariais. Apesar de receberem um salário que se situa acima da média no mercado local, os trabalhadores das montadoras no sul fluminense ainda recebem menos do que aqueles do ABC paulista, por exemplo. Essa tem sido uma questão candente para os trabalhadores locais e estimulado conflitos, ainda que as montadoras venham logrando êxito nesse quesito e mantendo a diferença salarial entre as localidades.

As estratégias gerenciais e a ação coletiva dos trabalhadores

Um elemento arrolado no cálculo das empresas foi o fato de que o sindicato, representante dos trabalhadores metalúrgico da região, se posicionava, diferentemente do passado, quando era orientado por práticas conflitivas, de forma muito mais afável e voltada à negociação. $\mathrm{O}$ sindicato, inclusive, sempre viu com bons olhos a chegada das montadoras, sendo isso percebido como possibilidade de ampliar o mercado de trabalho, as bases de representação e a importância da entidade no cenário sindical.

Para as empresas, esse era um sinal positivo e uma indicação de que não experimentariam um outro $\mathrm{ABC}$. Como já dissemos, a força da 
Ruptura geracional induzida e estratégias de gestão...

militância deste sindicalismo paulista foi um dos motivos para que as empresas buscassem explicitamente outras regióes, com pouca tradição de participação operária e baixa densidade sindical. Nesse quesito, a localidade fluminense apresentava-se também como terreno fértil aos olhos das montadoras.

Muitos fatores concorreram para isso. Primeiro, apesar da proximidade geográfica com Volta Redonda e a CSN - tradicional centro regional da indústria siderúrgica -, nem Resende nem Porto Real tiveram, em seu histórico, uma classe operária metalúrgica ligada à indústria automotiva. Segundo, a atuação sindical nesses dois municípios sempre representou uma pequena porcentagem das açôes do Sindicato dos Metalúrgicos de Volta Redonda, cujas principais atividades sempre estiveram ligadas à CSN, maior base da categoria na região. Por último, mas não menos importante, o fato de o Sindicato, àquela altura, estar filiado à Força Sindical, central com perfil mais conservador, afeita à prática de um sindicalismo de conciliação.

A posição do Sindicato foi percebida e utilizada pela empresa, que o sentiu receptivo, facilitando uma aproximação muito boa. De acordo com o gerente de instalação da PSA Peugeot Citroën, a firma teve um contato, na CSN, com o sindicato da região, e o mesmo teria sido muito positivo. A empresa sabia que a Força Sindical era menos agressiva.

Contudo, toda estratégia precisa ser avaliada, entre outras coisas, à luz de seus próprios desenvolvimentos. $\mathrm{O}$ setor de gerência da empresa já tinha a noção de que aquela busca de áreas de baixa densidade sindical tinha limites no tempo. Segundo o gerente mencionado antes, eles não tinham ilusão "porque o sindicato hoje é assim pela presença discreta das empresas do setor aqui. Quando a presença for maciça, certamente nós vamos ter um sindicato com um comportamento diferente".

De todo modo, a chegada da PSA (e da Volkswagen) mudou de forma sensível a paisagem social, política e econômica do sul fluminense. Um dos impactos mais notados diz respeito exatamente à representação dos trabalhadores metalúrgicos da localidade, o que parece ter sido a tônica também em outras regiōes (Nabuco, Neves \& Carvalho Neto, 2002). A instalação das montadoras trouxe novos desafios ao Sindicato dos Metalúrgicos de Volta Redonda, tradicional representante dos interesses dos operários da região. 
Antes do funcionamento da PSA, em 2001, o quadro organizativo e de mobilização dos trabalhadores na localidade estava praticamente todo vinculado à Vw (Ramalho, 1999; Ramalho \& Santana, 2001, 2002), que começou a funcionar em 1996. Porém, ele tendeu a intensificar-se bastante com a instalação crescente de outras empresas na região, associadas direta ou indiretamente às montadoras. $\mathrm{O}$ cenário tornou-se ainda mais complexo com as duas empresas em atividade.

$\mathrm{O}$ fato de se posicionar favoravelmente à chegada das montadoras e de assumir uma postura mais conciliatória não impediu que o sindicato fosse rapidamente levado a dar conta das demandas efetivas dos trabalhadores, desde o início do funcionamento das empresas, e enfrentar as particularidades das suas culturas gerenciais. E, acima de tudo, tendo de lidar com um conjunto de operários jovens com o perfil já descrito anteriormente. Vale dizer que, apesar dos cálculos e expectativas das empresas acerca dos trabalhadores mais jovens, sem vínculos e experiência, tanto pela situação concreta do local de trabalho, como por outros processos de socialização política e identitária, esses trabalhadores jovens não deixaram de produzir estratégias de resistência e conflito.

A vw teve de enfrentar, logo no início de suas atividades, as demandas dos trabalhadores por melhores condiçôes salariais e de trabalho. Os conflitos, até então de caráter mais pontual, culminaram em uma greve que resultou na constituição da Comissão de Fábrica (Ramalho \& Santana, 2001, 2002; Francisco, 2005). A empresa tinha, em outras plantas no país, esse tipo de organização de chão de fábrica, estando mesmo incluída como um dos pontos de sua carta social mundial. Contudo, no sul fluminense, isso não era respeitado, situação que mudou a partir da pressão dos trabalhadores.

Tendo conseguido sua organização dentro da empresa, os trabalhadores se conectaram não apenas com outros das plantas da empresa no país, mas também com esse tipo de organização pelo mundo, em localidades em que a empresa atua, através do Comitê Mundial de Trabalhadores da Vw (Barbosa, 2002). Nesse sentido, rompia-se, ou ao menos se minava, a estratégia de isolamento proposta pela empresa aos seus trabalhadores.

Nos encontros de trabalhadores da VW, os jovens operários de Resende estabeleceram contatos muito estreitos com os representantes 
Ruptura geracional induzida e estratégias de gestão...

dos trabalhadores da fábrica do $\mathrm{ABC}$ paulista. As trocas alimentaram as relações a ponto do boletim dos metalúrgicos do $\mathrm{ABC}$ passar a ser distribuído no interior da planta de Resende. Duas experiências diferentes e distantes se aproximaram e articularam, eliminando a distância espacial de $150 \mathrm{~km}$. O brownfield encontrava o greenfield. A força militante e a tradição do $\mathrm{ABC}$ encontravam a juventude e a novidade de Resende, política, material e simbolicamente.

O que ocorreu foi que o processo de socialização política, parte constitutiva do processo de formação de classe, que opera dentro e fora do espaço fabril, fez com que os jovens trabalhadores de Resende interagissem e se apropriassem de códigos que lhes estavam postos no interior de um determinando campo de organização e mobilização.

Não seria exagero dizer que as trocas com o ABC deram combustível a uma radicalização das atividades da comissão de Resende. A comissão tem sido elemento importante de sustentação das práticas do sindicato em sua luta por melhores salários e condições de trabalho, situação que, obviamente, tem recebido dura resistência por parte das empresas.

De todo, apesar do êxito da empreitada, deve-se dizer que esse processo não se deu sem tensões. A relação em um dado momento foi tão estreitada que gerou conflitos, tendo em vista que o sindicato de Resende, como apontado, era filiado à Força Sindical, central sindical que disputava com a Central Única dos Trabalhadores (CUT) - à qual o sindicato de São Bernardo também é filiado - os espaços de direção do movimento sindical brasileiro.

A experiência dos trabalhadores da PSA é um tanto distinta. No que diz respeito à ação sindical, percebem-se algumas tentativas de organização e mobilização por parte dos operários da montadora francesa, o que, no entanto, não tem sido tarefa fácil (Ramalho \& Santana, 2006a). Os trabalhadores têm enfrentando situações muito duras referentes à sua ação dentro e fora da empresa e à discussão sobre as relações de trabalho.

Nesse ponto, pode-se traçar um paralelo direto com o caso francês, já que o desenvolvimento de práticas anti-sindicais e de limitação da organização dos trabalhadores marca a trajetória gerencial da montadora francesa. Nos anos de 1970, por exemplo, assumindo uma postura repressiva, a empresa tratou os representantes dos trabalhadores 
com práticas que incluíam todo tipo de humilhação, em termos profissionais e entraves à sua ação sindical (Hatzfeld, 2002). Nesse sentido, a militância sindical e o engajamento organizativo lhes custavam caro. Já no contexto da reestruturação da empresa, Beaud e Pialoux (2004) indicam as dificuldades, passadas e atuais, do sindicato em buscar um agenciamento das demandas operárias, visando à construção de atores coletivos, diante das práticas da companhia.

Em Porto Real, diferentemente da direção da vw, que resistiu de início, mas acabou cedendo e aceitando uma comissão de trabalhadores no interior da fábrica, a PSA tornou difíceis todas as iniciativas de articulação operária no chão de fábrica.

Isso pode ser verificado nos empecilhos impostos à entidade de classe para chegar aos operários da linha de produção e no baixo percentual de sindicalização dos trabalhadores, especialmente se comparado com a unidade vizinha da vw. Além disso, a tentativa de criar mecanismos de organização no local de trabalho sempre enfrentou a resistência empresarial, que tem logrado garantir o êxito dessa estratégia.

O processo de implantação e o funcionamento da PSA Peugeot Citroën em Porto Real, apesar de suas particularidades, guardam, portanto, certa similaridade com a experiência analisada por Beaud e Pialoux (2004) e podem revelar um padrão de relacionamento da empresa com seus operários, independentemente das fronteiras nacionais, que é a marca de sua cultura gerencial.

\section{Considerações finais}

A análise das estratégias gerenciais implementadas pelas montadoras no sul fluminense indica que as mesmas tiveram êxito em termos de sua implantação. Contudo, não se pode dizer que esse êxito tenha sido total e pleno. A estratégia utilizada logo no processo de implantação, que tinha a ver com o recrutamento de jovens, pode ter surtido efeito no sentido de conseguir filtrar aqueles que as empresas consideravam, a partir de seus referenciais, não empregáveis, e no que diz respeito ao possível rendimento técnico. Contudo, nem por isso podemos deixar de assinalar que, em termos políticos mais amplos, no sentido de evitar que os jovens sem tradição de organização e militância se engajassem, ela não foi tão bem sucedida, sobretudo no caso da Volkswagen. 
Ruptura geracional induzida e estratégias de gestão...

Apesar de todas as chances que teve de produzir uma classe operária a sua feição, muito rapidamente, por questóes locais, nacionais e globais, a empresa teve de lidar com a construção de identidades operárias, que cruzaram a espacialidade física e as fronteiras políticas e etárias. A estratégia de priorizar os jovens, no caso do Sul fluminense, apesar das semelhanças, guardou alguma distinção frente a outras experiências, como a francesa, por exemplo.

$\mathrm{Na}$ Europa, as plantas sofreram, primeiro, um processo de reestruturação. As geraçôes estiveram, em algum momento, combinadas, como nos mostram Beaud e Pialoux (2004). No caso do Rio, as plantas já surgiram reestruturadas. Assim, elas não tiveram de se preocupar com o que fazer com aqueles trabalhadores "mais velhos" que já trabalhavam para ela e tiveram de se confrontar com a "corrosão" de seu mundo. Na localidade estudada, as empresas tiveram a chance de "começar do zero", em termos de formação de classe, cuidando apenas para que aqueles que ela considerava indesejáveis não burlassem seus filtros de recrutamento. Ao recrutar jovens locais e de "alta" escolarização, em uma área sem ou com pouca tradição, as empresas produziram uma barreira que filtrou em muito a entrada de trabalhadores mais experientes.

Porém, lembremos que, com todo esse esforço para produzir uma fábrica de jovens e "despolitizada", com a pretensão implícita de que isso, para além de todas as justificativas técnicas explícitas, reduziria as chances de conflitos, construçôes e ações coletivas, não foi o que se viu. Ao contrário, baseados em redes novas e tradicionais, locais e globais, esses jovens foram muito rapidamente lançados no interior das construções identitárias, percebendo claramente as formas pelas quais estavam sendo tratados pelas empresas, e souberam seguir caminho alternativo àquele que era o esperado pelas empresas, demandando das mesmas melhores condições de trabalho.

Recebido em maio de 2010 e aprovado em junho de 2010.

\section{Nota}

1. Deve-se lembrar, contudo, conforme indicado por Salerno et al. (2002), que, se o mapa da produção automobilística está bem mais descentrado de São Paulo, espalhando-se por vários outros estados e regiōes, este estado ainda mantém sua centralidade 
não só em termos de número de empresas e trabalhadores, mas também no que tange a atividades importantes de agregação de valor no interior da cadeia produtiva.

\section{Referências}

ABREU, A.; BEYNON, H.; RAMALHO, J.R. The dream factory. Work, Employment and Society, Cambridge, UK, v. 14, n. 2, p. $265-$ 282, June 2000.

ARBIX, G. Guerra fiscal e competição intermunicipal por novos investimentos no setor automotivo brasileiro. Dados, Rio de Janeiro, v. 43 , n. 1, p. $5-43,2000$.

BARBOSA, M.S. Sindicalismo em tempos de crise: a experiência na Volkswagen do Brasil. Santo André: Alpharrabio, 2002.

BEAUD, S.; PIALOUX, M. Retour sur la condition ouvrière: enquête aux usines Peugeot de Sochaux-Montbéliard. Paris: Fayard, 2004.

BOITO JUNIOR, A. Politica neoliberal e sindicalismo no Brasil. São Paulo: Xamã, 1999.

CARDOSO, A. Sindicatos, trabalhadores e a coqueluche neoliberal: a era Vargas acabou? Rio de Janeiro: FGV, 1999.

CASTRO, N.A. Reestruturação produtiva, novas institucionalidades e negociação da flexibilidade. São Paulo em Perspectiva, São Paulo, v. 11, n. 1, p. 3-8, 1997.

DELUIZ, N.; SOUZA, D.B.; SANTANA, M.A. Novos cenários produtivos e a educação profissional: a perspectiva das centrais sindicais. Boletim Técnico do SENAC, Rio de Janeiro, v. 26, n. 2, maio/ago. 2000.

FRANCISCO, E.M.V. A Comissão Enxuta: ação política na fábrica do consórcio modular em Resende. Bauru: Edusc; São Paulo: AnPocs, 2005.

HATZFELD, N. Les gens d'usine: 50 ans d'histoire à Peugeot-Sochaux. Paris: L'Atelier, 2002.

NABUCO, M.R.; NEVES, M.A.; CARVALHO NETO, A.M. (Org.). Indústria automobilística: a nova geografia do setor produtivo. Rio de Janeiro: DP\&A, 2002. 
Ruptura geracional induzida e estratégias de gestão...

RAMALHO, J.R. Organização sindical e a instalação de novas fábricas do setor automotivo: o caso do sul fluminense. In: Rodrigues, I. (Org.). Novo sindicalismo vinte anos depois. Petrópolis: Vozes; São Paulo: EDUC; UNITRABALHO, 1999. p. 90-115.

RAMALHO, J.R.; SANTANA, M.A. Promessas e efeitos práticos da implantação da indústria automobilistica no sul fluminense. In: ENCONTRO ANUAL da ANPOCS, 25., 2001, Caxambú.

RAMALHO, J.R.; SANTANA, M.A. A indústria automobilística no Rio de Janeiro: relações de trabalho em um contexto de desenvolvimento regional. In: Nabuco, M.R.; Neves, M.A.; Carvalho Neto, A.M. (Org.). Indústria automobilística: a nova geografia do setor produtivo. Rio de Janeiro: DP\&A, 2002. p. 107-121.

RAMALHO, J.R.; SANTANA, M.A. Flexibilidade à francesa: trabalhadores na Peugeot-Citroën brasileira. Tempo Social, São Paulo, v. 18, n. 1, p. 115-132, 2006a.

RAMALHO, J.R.; SANTANA, M.A. Um perfil dos trabalhadores do consórcio modular. In: Ramalho, J.R.; Santana, M.A. (Org.). Trabalho e desenvolvimento regional - efeitos sociais da indústria automobilística. 1. ed. Rio de Janeiro: Mauad, 2006b. v. 1, p. 75-90.

SALERNO, M. et al. A nova configuração da cadeia automotiva brasileira. São Paulo: EPUSP; PRO; TTO; BNDES, 2002. (Relatório de Pesquisa) (mimeo.).

SANTANA, M.A. As centrais sindicais brasileiras e a reestruturação produtiva: análises e propostas. Sociologias, Porto Alegre, n. 4, p. 120 137, 2000 .

SANTANA, M.A. Trabalhadores e política no sul fluminense: a experiência de Volta Redonda nos anos de 1980. In: Ramalho, J.R.; Santana, M.A. (Org.). Trabalho e desenvolvimento regional: efeitos sociais da indústria automobilística no Rio de Janeiro. Rio de Janeiro: Mauad, 2006. p. 110-128.

SOUZA, D.B.; SANTANA, M.A.; DELUIZ, N. Trabalho e educação: centrais sindicais e reestruturação produtiva no Brasil. Rio de Janeiro: Quartet, 1999. 
TOMIZAKI, K. A herança operária entre a fábrica e a escola. Tempo Social, São Paulo, v. 18, n. 1, p. 153-171, 2006.

TOMIZAKI, K. Ser metalúrgico no $A B C$ : transmissão e herança da cultura operária entre duas gerações de trabalhadores. Campinas: Centro de Memória da UnICAMP; Arte Escrita, 2007. 
